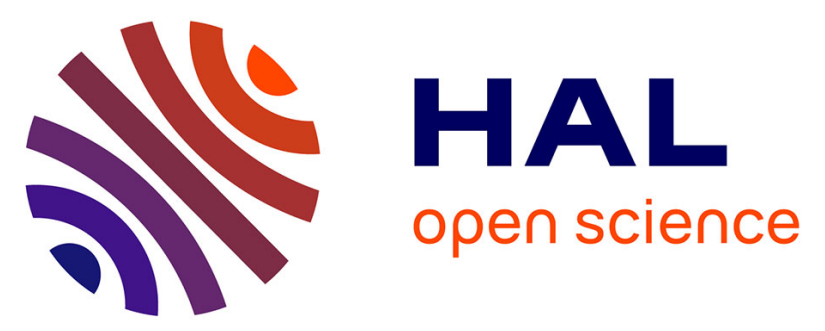

\title{
EBSD for analysing the twinning microstructure in fine-grained TWIP steels and its influence on work hardening
}

\author{
David Barbier, N. Gey, Nathalie Bozzolo, S. Allain, M. Humbert
}

\section{- To cite this version:}

David Barbier, N. Gey, Nathalie Bozzolo, S. Allain, M. Humbert. EBSD for analysing the twinning microstructure in fine-grained TWIP steels and its influence on work hardening. Journal of Microscopy, 2009. hal-02402444

HAL Id: hal-02402444

https: / hal-mines-paristech.archives-ouvertes.fr/hal-02402444

Submitted on 10 Dec 2019

HAL is a multi-disciplinary open access archive for the deposit and dissemination of scientific research documents, whether they are published or not. The documents may come from teaching and research institutions in France or abroad, or from public or private research centers.
L'archive ouverte pluridisciplinaire HAL, est destinée au dépôt et à la diffusion de documents scientifiques de niveau recherche, publiés ou non, émanant des établissements d'enseignement et de recherche français ou étrangers, des laboratoires publics ou privés. 


\title{
EBSD for analysing the twinning microstructure in fine-grained TWIP steels and its influence on work hardening
}

\author{
D. BARBIER* ${ }^{*}$, N. GEY*, N. BOZZOLO*, S. ALLAIN† \\ \& M. HUMBERT* \\ *Laboratoire d'Etude des Textures et Application aux Matériaux (LETAM), UMR CNRS 7078, \\ Université Paul Verlaine - Metz, 57000 Metz, France \\ $\dagger$ ArcelorMittal Research SA, Voie Romaine, BP 30320, 57283 Maizières-les-Metz, France
}

Key words. EBSD, steel, tensile deformation, twinning, TWIP.

\begin{abstract}
Summary
A $22 \mathrm{Mn}-0.6 \mathrm{C}$ twinning induced plasticity steel with an average grain size of $2.6 \mu \mathrm{m}$ was deformed in tension at room temperature. The electron backscattered diffraction technique was used to characterize the twinning structure in relation with the local texture evolution. For nanoscale analysis, additional transmission electron microscopy analysis was performed. Nanotwins were activated in the largest grains from the beginning of the deformation. They interacted with a well-developed dislocation structure that induced detectable intragranular orientation variations. With increasing deformation, dense bundles of nanotwins preferentially developed in grains oriented close to the $<111>/$ /tensile direction fibre (promoted by the deformation) as well as medium to high angle sub-boundaries. These key features of the twinned microstructure were finally related to the remarkably high strain hardening, which evolved according to different stages.
\end{abstract}

\section{Introduction}

Research by the steel industry focuses mainly on high strength steels with excellent formability. This optimal combination is particularly attractive for automotive applications such as structural reinforcements and energy absorption parts. The increased strength enables the weight of car bodies to be reduced and the increased ductility permits complex components to be designed. Among the wide variety of recently developed steels, high manganese austenitic steels with low stacking fault energy (SFE) are particularly promising, especially when mechanical twinning occurs (Grassel et al.,

Correspondence to: David Barbier. Tel: +33-(0)3-87-70-42-53; fax: +33-(0)3-8770-47-12; e-mail: david.barbier@arcelormittal.com
2000; Scott et al., 2005). High ductility and mechanical resistance are then obtained as a result of high work hardening (Asgari et al., 1997). However, the mechanisms at the origin of high hardening are still under discussion (Dastur \& Leslie, 1981; Adler et al., 1986; De Almeida et al., 1998). Some authors attribute the hardening to dynamic strain aging mechanisms, interpreted as the interaction between $\mathrm{C}-\mathrm{Mn}$ bonds and mobile dislocations (Adler et al., 1986; Shun et al., 1992; Hutchinson \& Ridley, 2006). Bracke et al. (2007) suppressed the dynamic strain aging in Fe-22 Mn$0.6 \mathrm{C}$ (composition given in mass \%) steels by substituting carbon by nitrogen, while keeping the SFE constant. The resultant mechanical properties were the same. Mechanical twinning can also improve the strain hardening. This socalled twinning induced plasticity (TWIP) effect is considered to result from a dynamical Hall-Petch effect (Rémy, 1978, 1981; Karaman et al., 2000; Allain et al., 2002; Allain, 2004). Allain et al. (2002) and Allain (2004)) suggested that the high strain hardening of Fe-Mn-C TWIP steels is mainly due to mechanical twinning. Recently, Bouaziz et al. (2008) showed the strong contribution of the kinematical hardening to the mechanical behaviour, which is linked to the TWIP effect.

In fact, the interpretation of strain hardening often suffers from a lack of information about the twinning microstructure induced by the deformation. In the literature, twins are mainly characterized by optical microscopy and by transmission electron microscopy (TEM) (Rémy, 1978 , 1981; Asgari et al., 1997; Karaman et al., 2000; Allain et al., 2002). However, optical microscopy offers only low spatial resolution and is not adapted to characterizing twins, especially in fine-grained materials. Conversely, transmission electron microscopy offers high spatial resolution, but the local nature of the data makes statistical deductions difficult. Nowadays, high-resolution electron backscatter diffraction (EBSD) analysis gives new possibilities for characterizing the deformed microstructure 
in relation with the texture evolution (Schwarzer, 1991; Humphreys, 2004). The aim of this research was (1) to evaluate the potential of the EBSD technique for characterizing the twins in fine-grained $\mathrm{Fe}-\mathrm{Mn}-\mathrm{C}$ TWIP steel deformed in tension and (2) to analyse the key features of the microstructure evolution that strongly influence the strain hardening.

\section{Experimental procedures}

\section{As-received material}

Fe-Mn-C TWIP steel was supplied by ArcelorMittal Research SA Maizières as a 1.3-mm-thick sheet. The alloy designation of the steel is $22 \mathrm{Mn}-0.6 \mathrm{C}$ (composition in mass percent, balance iron). The high manganese content stabilizes the austenitic phase at room temperature and decreases the SFE to about $20 \mathrm{mJm}^{-2}$ (Allain et al., 2004; Scott et al., 2005). Consequently, mechanical twinning occurs during deformation at room temperature (Allain et al., 2004; Scott et al., 2005). At lower temperature, as the SFE is decreased, $\varepsilon$ martensite is formed.

The $\gamma$-grains were equiaxed with an average size of $2.6 \mu \mathrm{m}$. However, the grain size varied widely from about 0.5 to $15 \mu \mathrm{m}$. Grains larger than $5 \mu \mathrm{m}$ were less numerous (about $10 \%$ ) but they represented $40 \%$ of the material surface. The texture was rather weak with a texture index of 1.23. This texture is described in detail by Barbier et al. (2008). The highest orientation densities are found around the copper $\{112\}<111>$, the Goss $\{110\}<001>$ and the brass $\{110\}<112>$ components (notation $\{\mathrm{hkl}\}<\mathrm{uvw}>$ with $\{\mathrm{hkl}\}$ being the crystallographic plane parallel to the rolling plane and $<$ uvw $>$ being the crystallographic direction parallel to the rolling direction).

\section{Tensile tests}

Tensile tests were conducted at room temperature by applying a strain rate of $10^{-3} \mathrm{~s}^{-1}$ (quasi-static loading conditions). The tensile direction (TD) was parallel to the sheet transverse direction. The gauge length was $80 \mathrm{~mm}$ and the width was $20 \mathrm{~mm}$. One tensile test was conducted up to the rupture (0.55 true strain). Six other tensile tests were conducted up to $0.02,0.05,0.10,0.20,0.30$ and 0.40 true strains. The true stress and inelastic strain were calculated. The normalized strain hardening rate defined as $\left(\frac{d \sigma}{d^{\varepsilon}}\right) / G_{0}$ was deduced from the true stress-strain curve fitted with a seventhorder polynomial function. The shear modulus $G_{0}$ was equal the 62 YPa according to the elasticity relation $G_{0}=\overline{2\left(\mathbb{F}^{\mathrm{F}}+v\right)}$ determined from the tensile experiments to $165 \mathrm{GPa}$ and $0.32 \mathrm{GPa}$, respectively. This normalization by $G_{0}$ is of interest to compare the strain hardening behaviour of different low SFE materials, as proposed by Asgari et al. (1997).

\section{EBSD and TEM characterizations}

EBSD was used to analyse the local texture evolution in relation to microstructural changes induced by the deformation (twinning and deformation substructure of the parent grain). High-resolution orientation maps were acquired in a 6500 F JEOL field emission gun-scanning electron microscope equipped with the Channel 5 EBSD system (HKL Technology, Abingdon, United Kingdom). EBSD scans were acquired with a beam step size comprised between 20 and $70 \mathrm{~nm}$. The samples were first prepared by standard grinding and polishing. For the most deformed samples, the surface was further polished by ion milling (BalTec RES 010) to improve the quality of the Kikuchi patterns. Despite this careful preparation, the Kikuchi pattern indexing rate decreased from $95 \%$ for the undeformed sample to $65 \%$ for the sample deformed to 0.55 true strain.

The EBSD data are displayed as Kikuchi pattern quality (KPQ) maps and additional orientation maps. The orientation colouring code is given by the unit triangle of the inverse pole figure (IPF) with TD projected in the cubic reference frame: grains misoriented by less than $20^{\circ}$ with respect to the $<100>,<110>,<111>/ /$ TD fibre orientations are red, green and blue, respectively. Moreover the non-indexed points remaining after the clean-up procedure are black on all orientation maps.

For the low strained samples, TEM investigations were also performed to take advantage of the higher spatial resolution and to highlight the nanotwins in the earlier stage of deformation as well as their interaction with the dislocations. The TEM (FEI CM200 operating at $200 \mathrm{kV}$ ) was equipped with a CCD camera for recording convergent beam electron diffraction patterns and coupled with an automated KosselKikuchi line based analysis (Fundenberger et al., 2002, 2003). This equipment allows acquiring orientation maps with a spatial and angular resolution of $10 \mathrm{~nm}$ and $0.1^{\circ}$, respectively.

The TEM samples were mechanically polished to $80 \mu \mathrm{m}$ in thickness. The TEM foils were electrolytically thinned to electron transparency by using a $5 \mathrm{vol} \%$ perchloric acid / 95 vol\% acetic acid solution under $30 \mathrm{~V}$ (Struers TENUPOL 3 (Struers, Ballerup, Denmark)). To check that the thin foil preparation did not induce the formation of artefact dislocations and mechanical twins, the as-received material was also prepared for TEM examination.

\section{Results}

\section{Tensile behaviour and corresponding work hardening}

The Fe-Mn-C steel exhibited outstanding mechanical properties combining high ductility and extraordinary strength. The ultimate tensile strength was $\approx 1000 \mathrm{MPa}$ and the elongation to rupture was $\approx 60 \%$. The true stress and the normalized strain hardening are plotted versus the true strain in Fig. 1(a) and (b), respectively. Markers indicating each 
a)

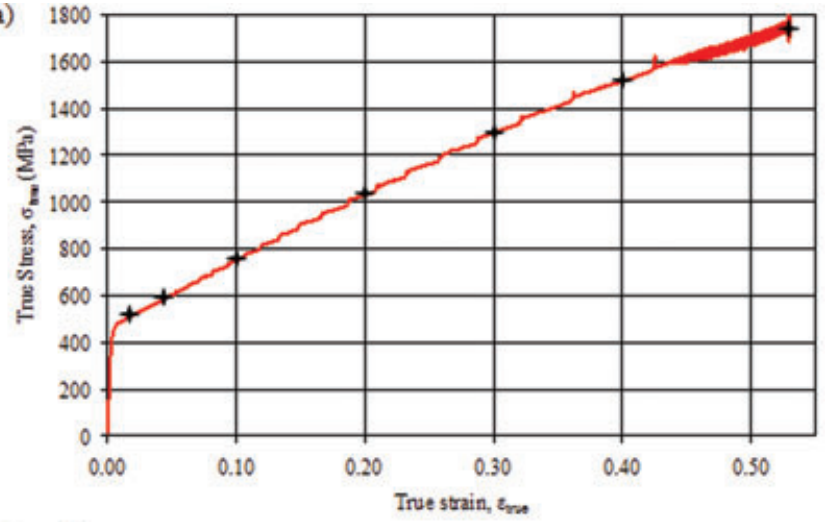

b)

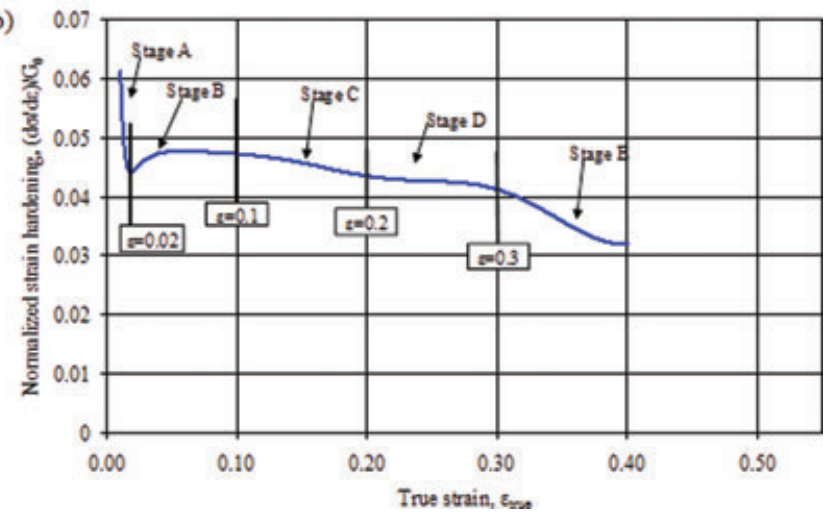

Fig. 1. (a) True stress-strain curve and (b) normalized strain hardening curve as a function of the true strain of the TWIP steel.

interrupted tensile test are overlaid on both curves. Serrations were observed on the stress-strain curve. They increased at large deformation and consequently the calculation of the strain hardening coefficient was limited to 0.40 true strain. It is well known that serrations occur on true stress-strain curves of high manganese austenitic steels. They have been interpreted as a result of dynamic strain aging mechanism or as Portevin-Le Chatelier effect (Dastur \& Leslie, 1981; Adler et al., 1986; De Almeida et al., 1998).

A remarkably high strain hardening was also observed (Fig. 1b). The amount of $(\mathrm{d} \sigma / \mathrm{d} \varepsilon) / G_{0}$ was greater than 0.04 up to 0.3 true strain. During the deformation, the strain hardening evolved according to different stages. From 0 to 0.02 true strain (stage A), $(\mathrm{d} \sigma / \mathrm{d} \varepsilon) / G_{0}$ decreased to 0.045 . Then the strain hardening increased to reach the first constant stage $\left((\mathrm{d} \sigma / \mathrm{d} \varepsilon) / G_{0}=0.048\right)$ from 0.02 to 0.1 true strain (stage B). A slight decrease (stage C) was followed by the second constant stage $\left((\mathrm{d} \sigma / \mathrm{d} \varepsilon) / G_{0}=0.043\right)$ from 0.2 to 0.3 true strain (stage D). Finally, over 0.3 true strain, the strain hardening decreased again (stage E) until rupture. This sustained high level of strain hardening, observed up to large strains, conferred high strength and ductility to this finegrained Fe-Mn-C TWIP steel.
Start of the twinning activity during work hardening stages $A$ and $B$

At 0.02 true strain, isolated twins were observed in some grains by TEM (Fig. 2a). The twins were 10 to $40 \mathrm{~nm}$ thick. This strain level coincided with the onset of stage B characterized by an increase of the strain hardening (Fig. 1). At 0.05 true strain, some grains had already activated two twin systems, see Fig. 2(b). The corresponding selected area electron diffraction patterns (Fig. 2c and d) and dark field images (Fig. 2e and f) give evidence of the existence of two twin systems. No $\varepsilon$ martensite was observed.

TEM orientation maps were also acquired to evaluate the intragranular orientation variations induced by dislocation interactions with obstacles (twin and grain boundaries). Figure 3 shows an example for the 0.05 strained sample. The beam step size was $50 \mathrm{~nm}$. Nanotwins were observed on the bright field image (Fig. 3a) but their orientations were not measured during the automated Kossel-Kikuchi line based analysis. Cumulative -point to origin- misorientations of $1 \% \mu \mathrm{m}$ were found within some grains (Fig. 3b). In the vicinity of the twin- and grain- boundaries, point-to-point misorientation angles can already reach $1.5^{\circ}$ to $3^{\circ}$ (Fig. $3 b$ ). These misorientation variations are linked to the high density of dislocations induced by the deformation and their spatial distribution over the grains. To better highlight these intragranular variations, additional maps revealing short- and long-range orientation gradients have been drawn. Figure 3(c) highlights long-range orientation gradients; the colour code is based on the angular deviation of the current orientation from the averaged grain orientation. Conversely, Fig. 3(d) highlights short range orientation gradients using the Kernel parameter for the first neighbours (Jorge-Badiola et al., 2007); this parameter is the average misorientation angle between the current pixel orientation and its eight first neighbours (misorientation angles higher than $5^{\circ}$ are excluded from the averaging procedure because they correspond to subboundaries). The short- or long-range orientation variations exhibited high values near the grain boundaries and to a lesser extent near the twin boundaries. In fact, larger distortions at grain boundaries than at the grain interiors (Fig. 3c) have often been reported and interpreted as a result of intense activation of slip systems near the grain boundaries to accommodate strain incompatibilities between neighbouring grains. The distortions observed in the vicinity of the twin boundaries can be linked to twin-slip interactions and may reveal the beginning of the dislocation pile up at the twin boundary.

A more statistical characterization of the twinning activity was obtained by EBSD. Figure 4 shows the result of an EBSD scan on the sample strained to 0.1 true strain. It was performed with a beam step of $60 \mathrm{~nm}$. As the twin thickness was smaller, the IPF map did not reveal the twin orientations. However, the presence of twins was revealed on the KPQ map by straight dark lines within some grains (Fig. 4a). Additional EBSD 

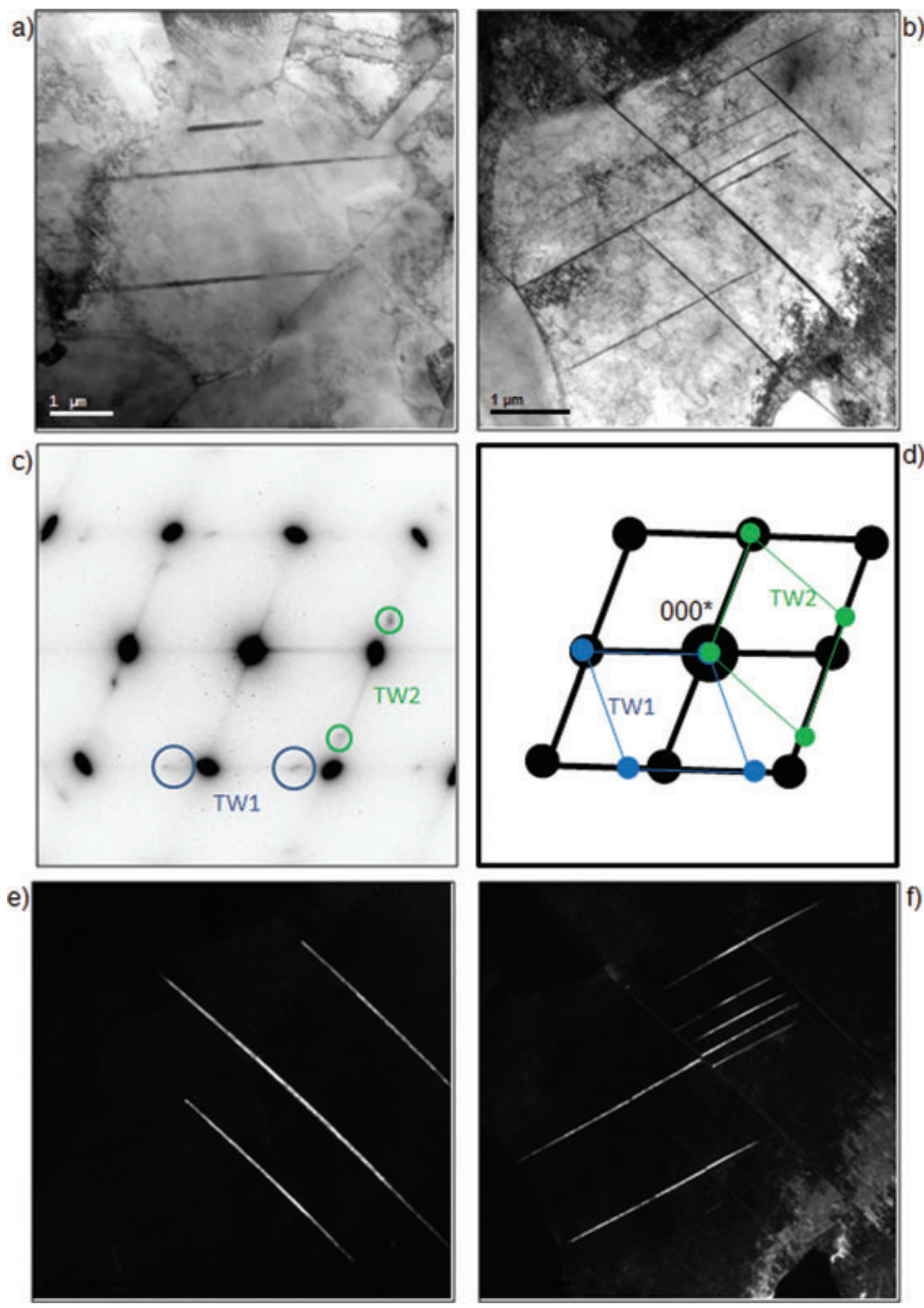

Fig. 2. TEM images illustrating the early twinning activity: (a) mechanical twins after 0.02 true strain, (b) two non coplanar twin systems after 0.05 true strain, corresponding (c) experimental and (d) simulated selected area electron diffraction patterns (the spots corresponding to each twin system are labelled TW1 and TW2, respectively) and (e and f) corresponding dark field images.

measurements were performed across these lines manually. Thus, we checked that the corresponding Kikuchi patterns contained the diffraction pattern of the twins that overlapped with the diffraction pattern of the parent grains.

This KPQ map shows that half of the grains had activated at least one set of parallel twins. These twins were preferentially observed in grains larger than $5 \mu \mathrm{m}$. Note that the local texture was very weak. The grains oriented close to the Goss and copper components (in green in Fig. 4b) were already present in the as-received material. The larger ones activated twins. Grains oriented close to the $<111>$ and $<100>/ /$ TD fibres (in blue and red in Fig. 4b, respectively) also contained twins. A classical trace analysis confirmed that the twin boundaries were parallel to a $\{111\}$ austenitic plane. Moreover we checked that the selected $\{111\}$ planes were those associated to the twin systems with the highest Schmidt factor.

The intragranular misorientations increased with the deformation. The orientation gradient can be of $3 \% \mu \mathrm{m}$ within 

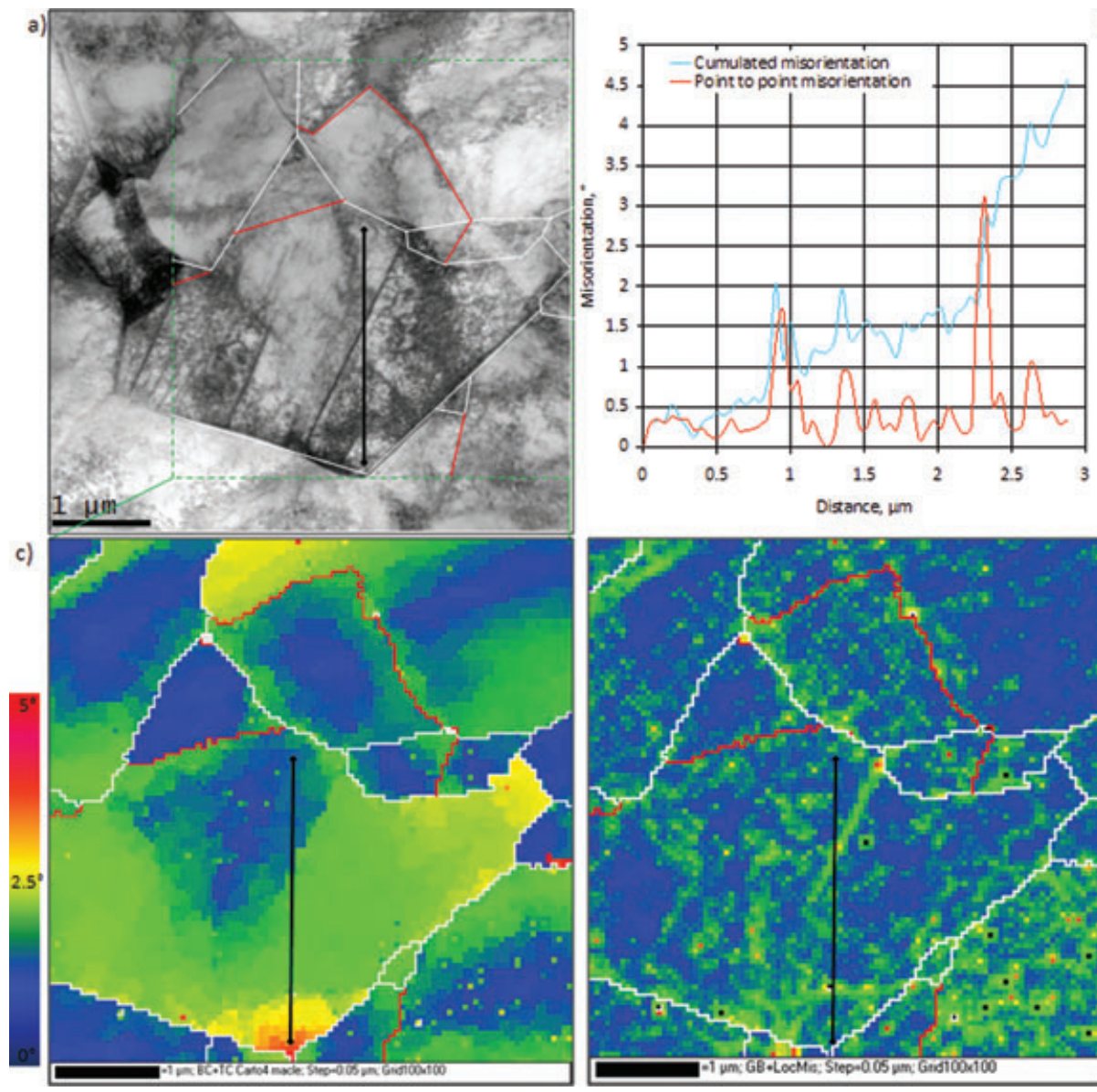

b)

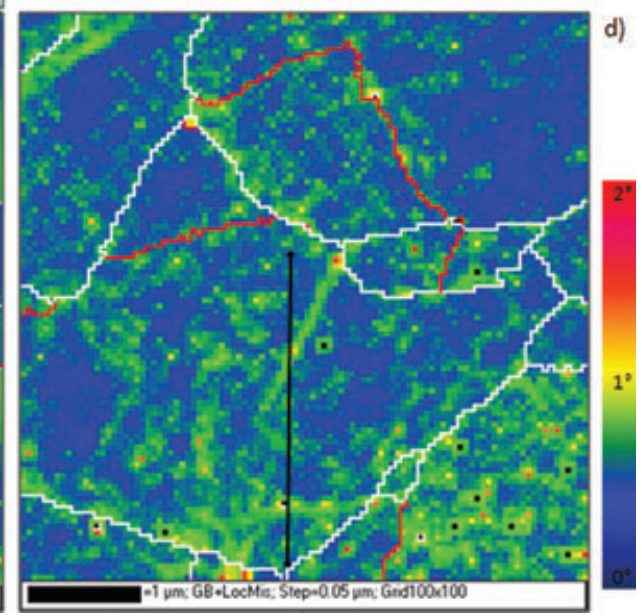

Fig. 3. TEM analysis of intragranular orientation variations: (a) corresponding bright field image, (b) misorientation profile along the black line in (a), (c) long-range orientation gradients revealed by a colour code based on the deviation of the current orientation from the averaged grain orientation, (d) short range orientation gradients revealed by a colour code based on the averaged misorientation angle between the current orientation and its surrounding.

some grains (Fig. 4c); it was of about $1 \% / \mu \mathrm{m}$ after 0.05 true strain (Fig. 3c). Similar misorientation profiles were observed in different grains. This indicates that the increase of intragranular misorientations with the deformation is a general trend. Such cumulative intragranular misorientations arise from the lattice curvature. They are associated to the formation of dislocations that accommodate the deformation gradient. With the increase of intragranular misorientations, the twin boundaries also showed detectable curvatures (see the black arrow in Fig. 4a). This bending is a consequence of the parent grain lattice curvature that produced a curvature of the $\{111\}$ twin plane. A misorientation analysis showed that the common $\{111\}$ plane normal between the parent grain and the twin rotated together along the twin boundary so that the twin relation was locally respected despite the bending.

Further aspects of the twinned microstructure during stages $C$ and $D$

Between 0.1 and 0.3 true strain, the EBSD analysis shows that the fraction of twins increased only slightly especially between
0.1 and 0.2 true strain. However, significant changes were observed for the twinning activity in relation with the texture evolution.

First, the twins created by further deformation developed different configurations. Twins belonging to the same system were clearly organized in bundles. With increasing deformation, the number of twins in the bundles increased but the apparent twin thickness remained between 10 and $40 \mathrm{~nm}$, as observed by TEM (Fig. 5). The twin orientations of the densest bundles were measured by EBSD, as seen in Figs 6 and 7 for the sample strained to 0.2 and 0.3 true strain, respectively. Some bundles were about $250 \mathrm{~nm}$ wide at 0.3 true strain. However, the parent austenitic layers between the twins were too small to measure their orientations by EBSD. Moreover, two twin systems were often activated, as shown in the KPQ map in Figs 6(a) and 7(a). Figure 8 illustrates the three main configurations observed between the twin systems. In grain $\mathrm{A}$, the twinning systems show an ear configuration indicating that they were activated concurrently in time. In grain $\mathrm{B}$, two systems were activated in different regions of the 
a)

b)

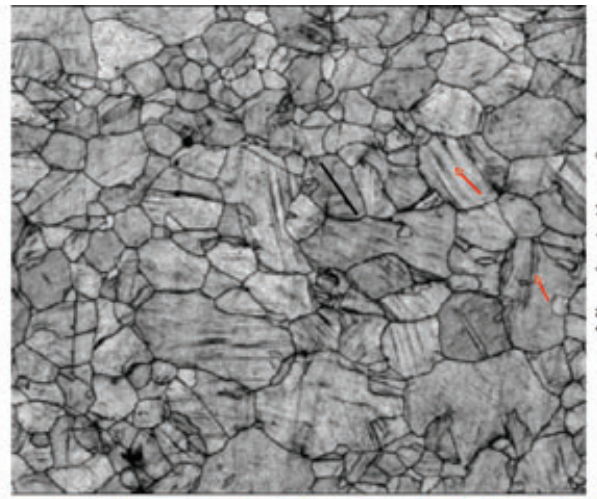

)

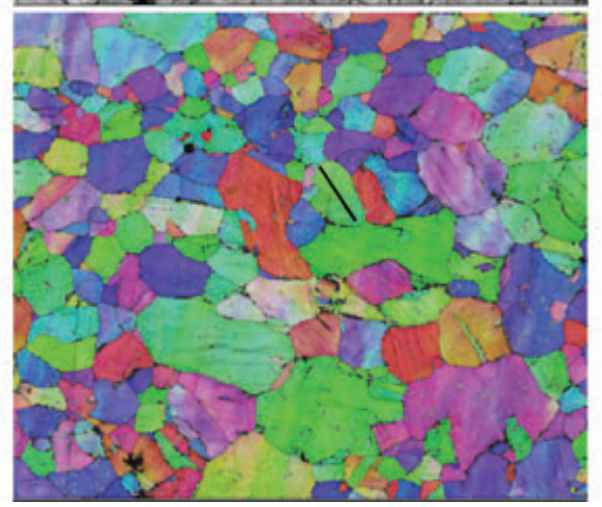

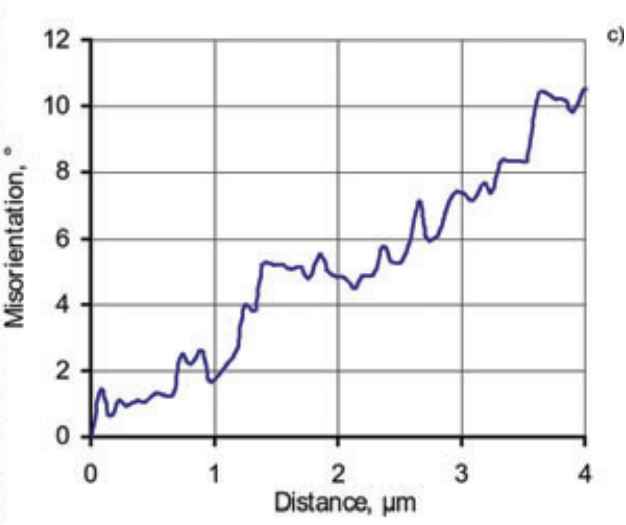

$10 \mu \mathrm{m}$

c)

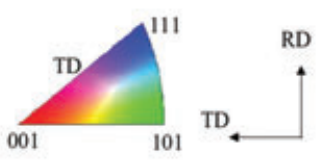

Fig. 4. EBSD maps of sample strained to 0.1 true strain: (a) KPQ map, (b) TD-IPF map and (c) cumulative misorientation profile along the black line drawn on the maps.

grain. In grain $\mathrm{C}$, they were sequentially activated forming a ladder-like configuration.

The second major change was the strong dependence between the grain orientations and twinning activity: the blue grains from the $<111>/ /$ TD fibre exhibited a higher fraction of twins than the red grains from the $<100>$ //TD fibre (Fig. 7). A small fraction of grains were still oriented close to the copper and Goss components (in green, $<110>/ / T D$ fibre). These grains also contained a well-developed twinning structure. However note that in this medium strain region, the texture strengthened around the $<111>/ /$ TD fibre. This evolution is clearly seen by comparing the fraction of the differently coloured grains in Figs 4(b) and 7(b).

To analyse the dependence of twinning on the grain orientation, iso-density lines of maximum Schmid factors for slip and twinning were plotted in the unit triangle of the TDIPF (the IPF orientation colour code is also given in semitransparency). Figure 9 highlights the orientation domains favourably oriented for slip and for twinning. Of course this representation considers neither the local stresses nor the a)

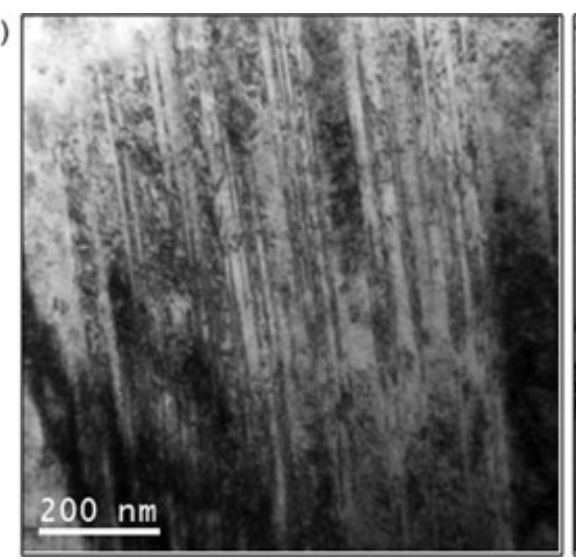

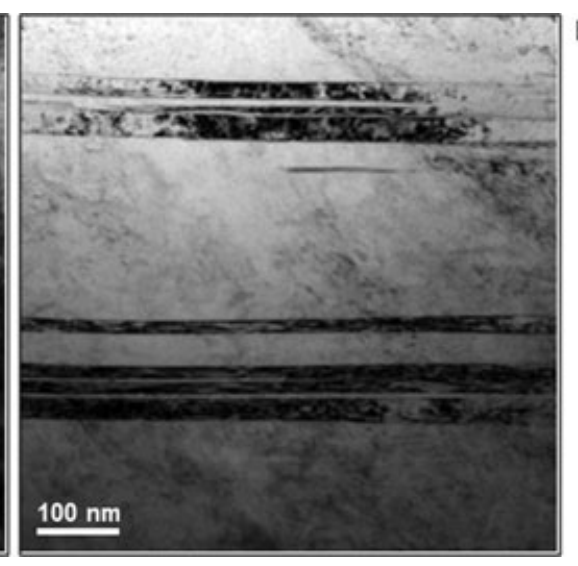

b)

Fig. 5. TEM bright field image of twins after 0.3 true strain. (a) Global and (b) detailed view of the twin bundles. 


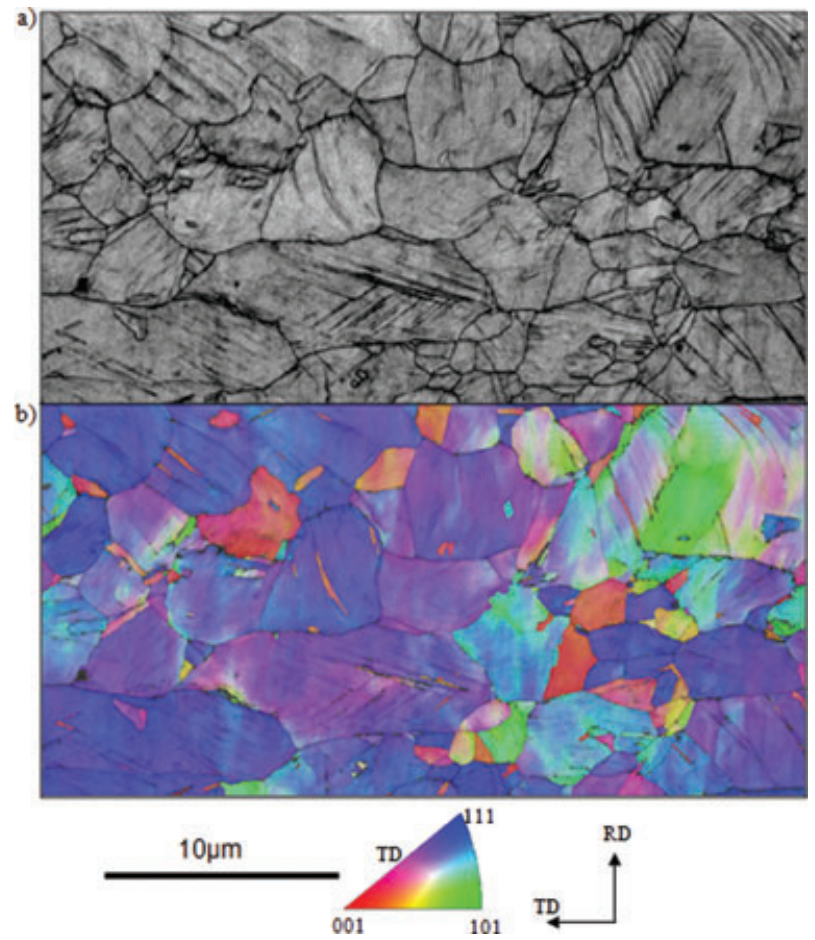

Fig. 6. EBSD maps of sample strained to 0.2 true strain: (a) KPQ map and (b) TD-IPF map.

critical resolved shear stress for slip and twinning. However, it confirms that grains in green in the IPF map $(<110>$ close to the TD) and, to a lesser extent, grains in blue $(<111>$ close to the TD) are better oriented for twinning than for slip. The opposite is seen for grains in red $(<100>$ close to the TD).

Finally, the last new feature was the development of medium to high angle boundaries within some deformed grains, especially in those oriented close to the $<110>/ /$ TD fibre (in green on the IPF maps). This is clearly seen in Figs 6 and 7 . Figure 10 gives a close-up of the grain marked by a white star in Fig. 7. The KPQ map (Fig. 10a) reveals a large number of sub-boundaries formed within the grain. The misorientation across these sub-boundaries was about $10^{\circ}$. Such substructure was neither observed in the as-received material nor in the low strained samples but appeared progressively with the strain increase. These sub-boundaries seemed to delimit different twin bundles (Fig. 10b) and progressively caused grain fragmentation. The sub-grains gradually rotated toward the deformation fibres (either $<111>$ - or $<100>/ / T D$ ) and behaved as new grains after a certain amount of deformation. The indexing rate of the map decreased to $75-80 \%$. This was mainly caused by the increased size and number of regions with strong lattice distortions (including the newly created boundaries).

The misorientations within the grains and sub-grains continued to increase (see Fig. 10c). In grains with a large orientation gradient, pronounced twin curvatures were

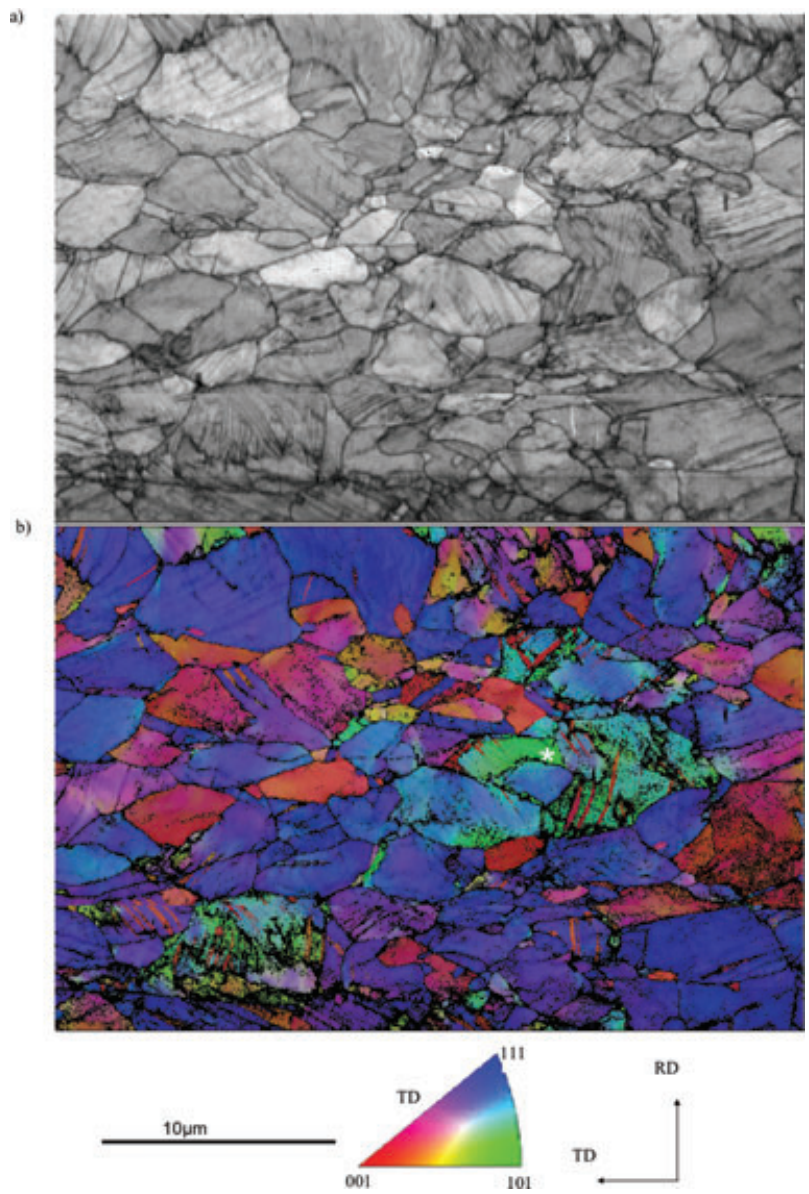

Fig. 7. EBSD maps of sample strained to 0.3 true strain: (a) KPQ map and (b) TD-IPF map.

observed. However the twin curvature was still observed to follow the $\{111\}$ plane curvature of the parent grain; at the twin boundary the twin orientation relation remained valid. As a consequence, the orientation gradient was similar at each side of the twin boundary with cumulative misorientations of about $4 \% \mu \mathrm{m}$. Thus large orientation gradient were observed within the twins. In the same way, twins of the same bundle were often misoriented. One can assume that the twins inherit the orientation spread of the deformed grain.

\section{Twinned microstructure during stage $E$}

Beyond 0.3 true strain, the volume fraction of twins increased markedly, with twin bundles becoming denser and larger. Figure 11 shows the KPQ and IPF maps of the sample strained to 0.4 true strain. The bundles appeared as large twinned domains of about $500 \mathrm{~nm}$. Comparing Figs 7(a) and 11(a) shows the increase in twinning activity from 0.3 to 0.4 true strain. Most of the grains in Fig. 11(b) were oriented close to $<111>/ /$ TD fibre promoted by the deformation. The grains with orientations close to the Goss and copper components had disappeared. The relation between the grain orientation 

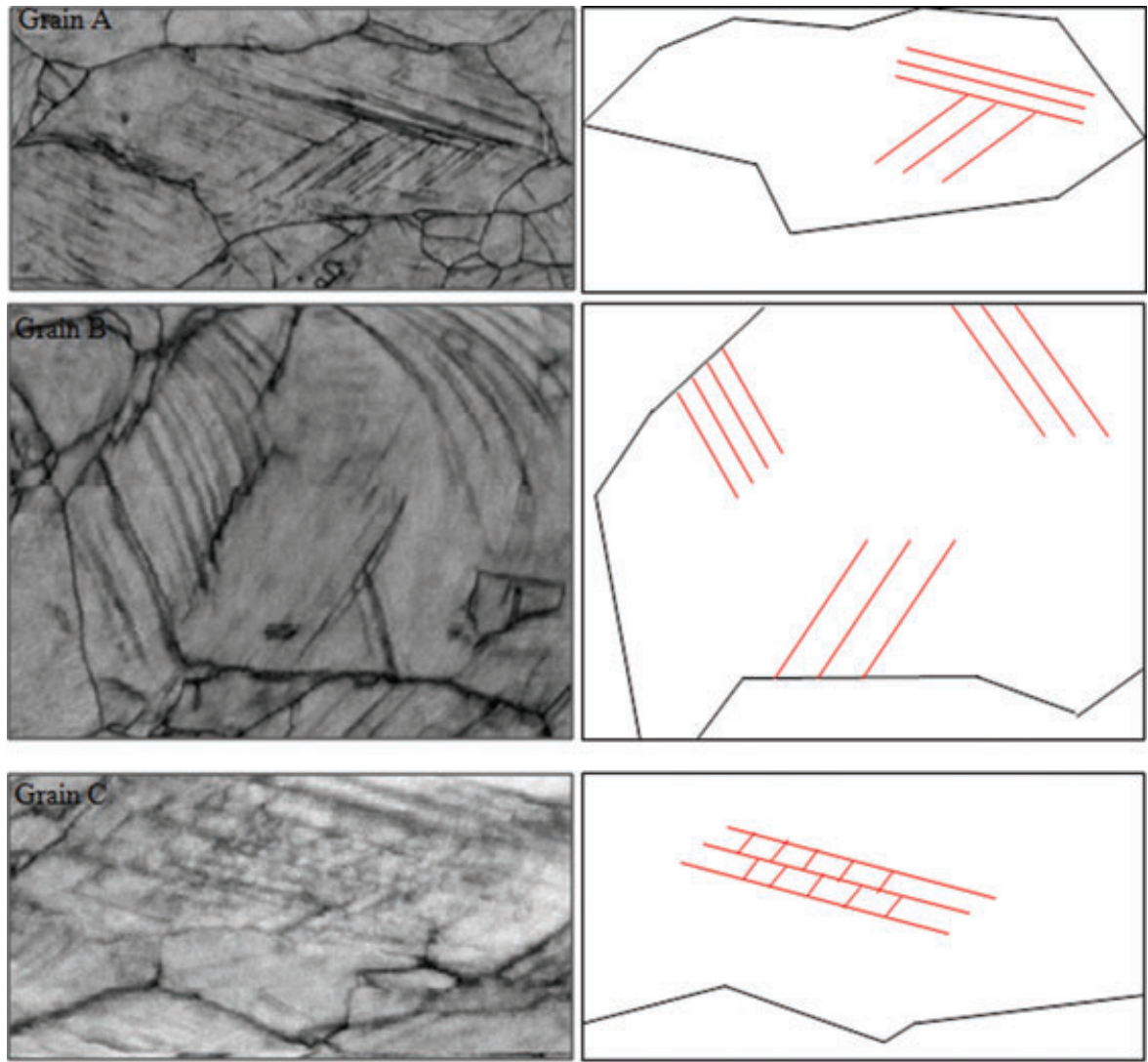

$5 \mu \mathrm{m}$

Fig. 8. KPQ maps highlighting specific grains with different twin configurations.

and the twinning activity was still observed. Grains from the $<111>/ /$ TD fibre exhibited a larger volume fraction of twins than those from the $<100>/ /$ TD fibre that were also less numerous. On the sample strained to 0.4 true strain, the orientations generated by twinning were analysed. As seen in Fig. 11(b), twins activated in the $<111>/ /$ TD oriented grains reinforced the $<100>/ /$ TD fibre whereas the little amount of twins activated in the $<100>/ /$ TD oriented grains reinforced the $<111>/ /$ TD fibre. As a consequence no new texture component appeared through twinning. The contribution of twin orientations to the bulk texture is further detailed in Barbier et al. (2008). Note also that the $<111>/ /$ TD oriented grains promoted by the deformation formed twins belonging to an orientation domain of easy slip (see Fig. 9).
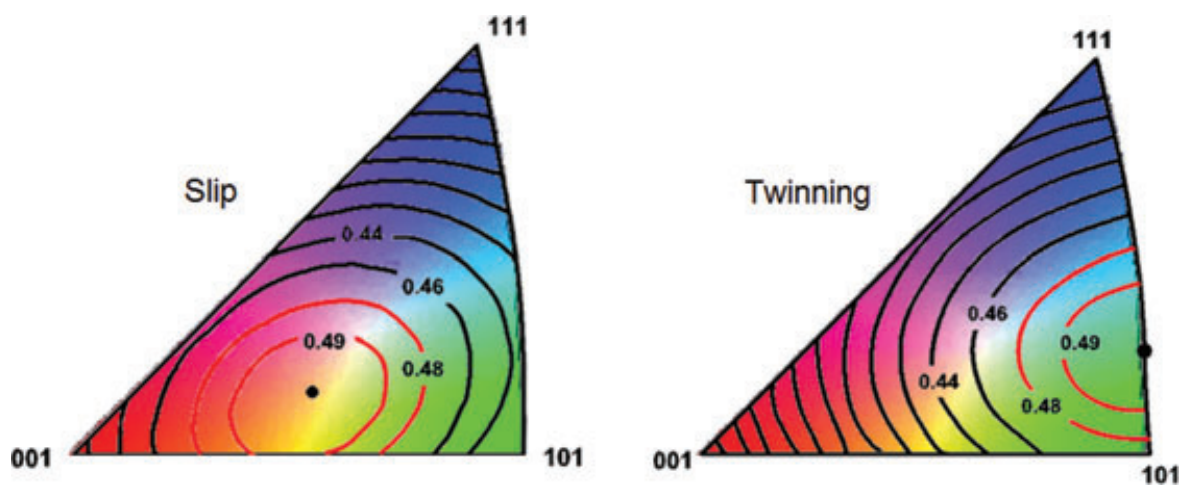

Fig. 9. Iso-density lines of maximum Schmid factors (a) for slip and (b) twinning plotted in the unit triangle of the TD-IPF (the IPF orientation colour code is also given in semi-transparency). 


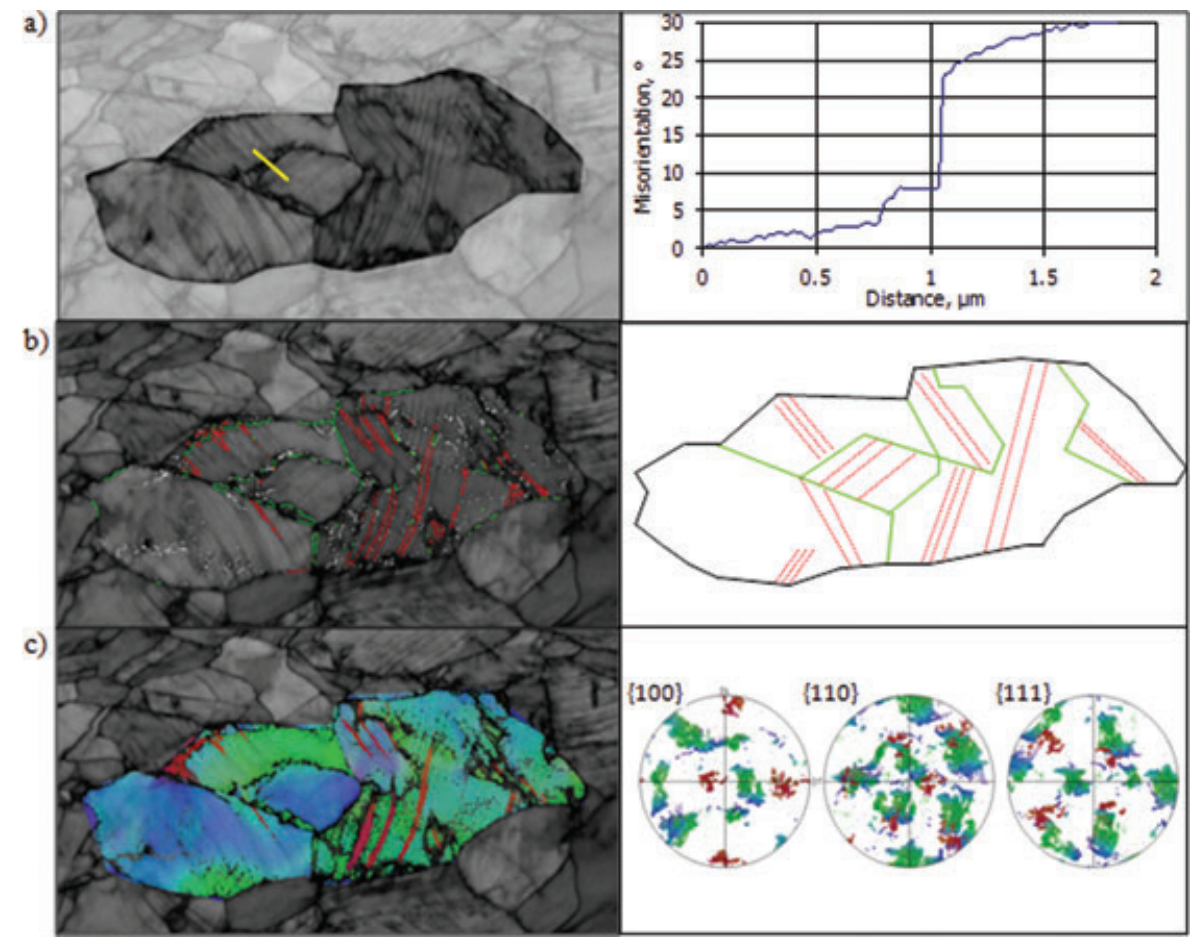

Fig. 10. Different EBSD representations corresponding to the grain marked by the white star in Fig. 7. (a) KQP map with the misorientation profile along the yellow line, (b) KPQ map with specific misorientation lines and corresponding schematic drawings: twin boundaries in red - grain boundaries misoriented by less than $3^{\circ}$ in white and less than $10^{\circ}$ in green and (c) TD-IPF map with the corresponding $\{100\}$, $\{110\}$, and $\{111\}$ pole figures.

Moreover, Fig. 11 reveals large regions that were not indexed because the diffraction patterns were of poor quality. They are coloured in dark grey and black in Fig. 11(a) and (b), respectively. In these regions, dense twinning activity and/or strong accumulation of dislocations induced strong lattice distortions. Unfortunately, with increasing regions of non-indexed points, it becomes impossible to perform a reliable analysis of intragranular misorientations.

\section{Discussion}

\section{EBSD analysis of the twinned microstructure}

Deformation twins are key features of the microstructure in TWIP steels, as they strongly influence strain hardening. The twinning activity is, however, difficult to analyse because the twins are nanometric and interact strongly with a welldeveloped dislocation structure. Our results show that highresolution EBSD is a powerful tool to obtain information about the microstructure in addition to TEM observations. It provides a better statistical characterization of the twinning activity in relation with the texture evolution, even in finegrained TWIP steels. The spatial resolution of EBSD is about $50 \mathrm{~nm}$ in fully recrystallized steels (Humphreys, 2001). TEM analysis showed that the twins have an apparent thickness between 10 and $40 \mathrm{~nm}$. Thus it is not surprising that their orientations are not determined by automated EBSD analysis, especially after low strain levels at which the twin bundles are not dense. Nevertheless their presence is detected by the grey level variations of the KPQ index. This index gives remarkable detail of the microstructure that is difficult to reveal by standard metallography (Humphreys, 2004). Of course, a careful surface preparation is required. With increasing deformation, the twin orientations of the densest bundles can be measured by EBSD. In fact, the twin density in the bundles increases and the twin orientation is predominant in the EBSD pattern of the probed volume. The opposite happens with the parent austenitic matrix remaining between the twins and consequently its orientation is mainly not measured. This is the reason why the twin thickness cannot be determined from the orientation EBSD map.

Nevertheless, EBSD allows one to study the interaction of the microtexture and the twinning activity, even for fine-grained TWIP steels. Early twinning could be favoured by the presence of Goss and copper orientations, characterized by high Schmid factors for twinning (Fig. 9). However, in the low strain region, twinning depends more on the size of the grain than on its orientation. Indeed, twins are observed mainly in grains larger than $5 \mu \mathrm{m}$ (Fig. 4). With increasing deformation, the Goss and copper oriented grains progressively rotate to develop the major $<111>/ /$ TD fibre and the minor $<100>/ /$ TD fibre. Again, grains from the main $<111>/ /$ TD fibre orientation 


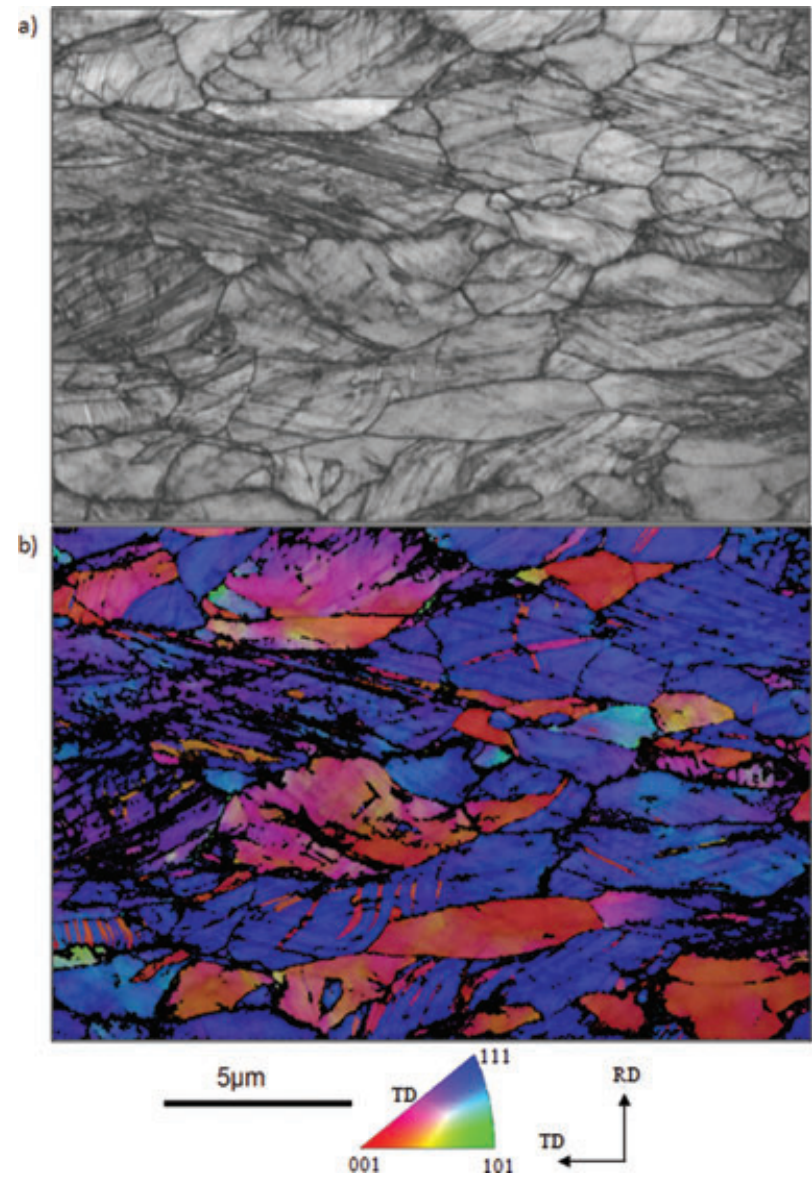

Fig. 11. EBSD maps of sample strained to 0.4 true strain: (a) KPQ map and (b) TD-IPF map.

are suitably oriented for twinning whereas those from the weak $<100>/ /$ TD fibre orientation are more adequate for slip. As the fraction of grains oriented close to the $<111>/ / \mathrm{TD}$ fibre steadily increases, twinning is continuously promoted by further deformation. This strong orientation dependence of twinning was also observed by Yang et al. (2006) and Meng et al. (2007). Thus the texture is an important parameter for controlling the twinning activity. As a consequence attention should be paid to the texture evolution during the sheet forming process to optimize the TWIP effect.

Ideally, the twin volume fraction is desired to interpret differences in the mechanical behaviour. Different methods have been proposed to estimate the twin volume fraction by EBSD and were applied to large-grained materials (Mason et al., 2002). The areal fraction deduced from the EBSD map can in a second step be processed using stereological analysis to deduce the volume fraction (Fanta \& Zaefferer, 2008). Unfortunately, for a material with bundles of nanotwins, EBSD alone is probably not adapted to reliably quantify the twin areal fraction. Indeed, for high strains, the bundles of nanotwins and the parent matrix in between are not resolved on the orientation maps. Moreover, the indexing rate in the twinned regions decreases with increasing deformation. In Barbier et al. (2008), we attempted to estimate the twin volume fraction by analysing the contribution of twin orientations to the bulk austenitic texture and by working out complementarities of $\mathrm{X}$-ray diffraction and EBSD data. The twin volume fraction was estimated to $9 \%$ at 0.55 true strain.

\section{Influence of the twinning microstructure on the work hardening}

Fine-grained Fe-Mn-C TWIP steel exhibits remarkably high strain hardening up to large strains (Fig. 1). This contribution shows that this sustained high work hardening evolves according to different stages related to specific features of the microtexture. After a pronounced decrease (stage A), the strain hardening increases to reach the first constant stage (stage B). TEM showed that the transition from stage A to stage B corresponds to the onset of twinning within grains previously deformed by slip (Fig. 2). Pronounced orientation variations are observed in the vicinity of the twin boundaries as a result of strong interactions between dislocations and twins. Thus the onset of twinning causes an increase in strain hardening in TWIP steels. The twins, even in low volume fraction, may reduce the effective grain size and act as strong obstacles for dislocation motions. In other low SFE materials, like nickel-cobalt-based alloys or $\alpha$-brass (Asgari et al., 1997; Kalidindi, 1998, 2001; El-Danaf et al., 1999), stage B also corresponds to the onset of twinning but is characterized only by a uniform constant strain hardening, without any increase. However, Mahajan \& Chin (1973) and Rémy (1978, 1981) considered that twin-slip interactions increase the strain hardening rate. A similar increase corresponding to the onset of twinning was also observed in high purity $\alpha$-titanium (Salem et al., 2003).

After this first increase, strain hardening decreases weakly (stage C). In fact, this weak decrease may be caused by the slowing down of the twinning activity. Twinning seems less active than before; the twins generated in the initial stage of deformation have decreased the grain size, and consequently a higher stress is necessary to generate new twins. In addition, the progressive lattice curvature of the parent grain (revealed by the cumulative intragranular misorientation profile) produces the bending of the twin boundaries what may also hinder the twin propagation within a bundle. Moreover, the texture remains very smooth and is not able to promote twinning through an orientation effect. Asgari et al. (1997) also suggested that the decreased strain hardening in low SFE Face-Centered Cubic (FCC) materials is related to the inhibition of twin formation (Hull, 1961; Christian \& Mahajan, 1995).

Then follows a second constant strain hardening (stage D). It is concomitant with two microstructural features. First, the twinning activity increases again. The applied stress is high enough for further twinning. Moreover, the texture evolves so that the densities of orientations suitable for twinning are 
reinforced; the number of grains from the $<111>$ //TD fibre orientation, adequate for twinning, increases continuously (Fig. 7). Second, most of the grains activate a secondary twinning system. Complex configurations arise between primary and secondary twins (Fig. 8). They reduce even more the mean free path of dislocations. The restarting of twin formation with the setting up of complex configurations maintains the strain hardening rate at a high level. The ladderlike configuration (Fig. 8) is expected to be the most efficient one for the dynamic Hall-Petch effect (Allain et al., 2002).

Note also that the $<111>/ /$ TD oriented grains promoted by the deformation form twins oriented for easy slip (see Figs 9 and 11). Moreover EBSD revealed a high orientation spread within the twinned domains. In Yang et al. (2006), it was argued that strong slip interactions can take place within the twins and that it contributes to strain hardening. However, in fine-grained TWIP steel it is less probable that the nanotwins are plastically deformed. As mentioned previously, the twin bending is linked to the parent lattice curvature. Moreover, the curvature radius regarding to the twin thickness is too important to result from the plastic deformation of the twin. The misorientation spread observed within the twinned domain is then probably inherited from the previously deformed matrix.

Finally, strain hardening continuously decreases up to rupture (stage E). However, the twin volume fraction increases strongly. The twin bundles become denser and thicker. At the same time, a pronounced localization of the deformation is observed; large regions with numerous dislocations develop. This contributes to the initiation of sample rupture.

Of course, deformation twinning is not the sole cause of high rates of hardening in low SFE materials (Asgari et al., 1997; Hutchinson \& Ridley, 2006; Hamdi \& Asgari, 2008). In TWIP steels, however, the formation of twins interacting with multiple slip is an important mechanism controlling the strain hardening. A numerical work based on a crystal plasticity model is in progress to assess the influence of twins on the mechanical behaviour in TWIP steels. The large set of data obtained by EBSD will assist in the development of this physically based model.

\section{Conclusion}

This research explores the contribution of EBSD to characterize the twinning microstructure in fine-grained $22 \mathrm{Mn}-0.6 \mathrm{C}$ TWIP steels and discusses the influence of twinning on the remarkably high work hardening during a tensile test.

EBSD performed in a field emission gun-scanning electron microscope was found to be a powerful tool for statistical characterization of the twinning activity in relation to the texture evolution, even in fine-grained material. This technique complements nanoscale analysis by TEM. For low deformation levels, the nanotwins observed by TEM are not detected on the orientation map. However, the twins are revealed by grey level variations on the KPQ map. Comparing two EBSD maps at different deformation levels allows one to qualitatively appraise the evolution of the twinning activity. With increasing deformation, dense bundles of nanotwins developed, whose orientations can now be measured by EBSD. As the texture strengthens with the deformation, a strong orientation dependence of twinning is observed. Among the fibre components promoted by the tensile deformation, grains from the main <111>//TD fibre orientation are suitably oriented for twinning whereas those from the weak $<100>$ //TD fibre orientation are more adequate for slip. This highlights the importance of texture evolution for better control of the twinning activity.

This detailed analysis of the microtexture, now possible by EBSD, is key to interpreting the contribution of twinning to the high work hardening of TWIP steel. First, the onset of twinning in the largest grains coincides with an increase in strain hardening at 0.02 true strain. This increase is probably promoted by strong twin-slip interactions. The subsequent weak decrease in strain hardening is concomitant with the pile up of dislocations that form sub-boundaries and the inhibition of further twin formation. In fact, the twins generated in the initial stage of deformation have decreased the grain size, and consequently a higher stress is necessary to generate new twins. A second constant strain hardening regime is then promoted by the restart of the twinning activity with increasing deformation. The formation of a secondary twin system within a large number of grains is even more efficient for reducing the mean free path of dislocations. Moreover, the texture evolves so that the densities of orientations suitable for twinning are reinforced. Finally even if the twinning activity is favoured up to the end of the deformation, large regions with strong accumulation of dislocations appear and initiate the sample rupture.

\section{Acknowledgements}

The authors thank ArcelorMittal Research SA for financial and technical support and for providing the material. The authors also thank Region Lorraine and CNRS for financial support, and the research team 'Material Forming' of Dr. V. Favier for fruitful discussions.

\section{References}

Adler, P.H., Olson, G.B. \& Owen, W.S. (1986) Strain hardening of Hadfield manganese steel. Metall. Mater. Trans. A 17A, 1725-1737.

Allain, S., Chateau, J.P., Bouaziz, O., Legros, M. \& Garat, X. (2002) Characterization of the mechanical twinning microstructure in a high manganese content austenitic steel. Proceeding of the Int. Conf. on TRIPAided High Strength Ferrous Alloys. Ghent, Belgium. GRIPS Proceeding. Allain, S. (2004) Caractérisation et modélisation thermomécaniques multiéchelles des mécanismes de déformation et d'écrouissage d'aciers austénitiques à haute teneur en manganèse-application à l'effet TWIP. PhD Thesis, INPL, France. 
Allain, S., Château, J.P., Bouaziz, O., Migot, S. \& Guelton, N. (2004) Correlations between the calculated stacking fault energy and the plasticity mechanisms in Fe-Mn-C alloys. Mat. Sci. Eng. A-Struct. 387, $158-162$.

Asgari, S., El-Danaf, E., Kalidindi, S.R. \& Doherty, R.D. (1997) Strain hardening regimes and microstructural evolutions during large strain compression of low stacking fault energy fcc alloys that form deformation twins. Metall. Mater. Trans. A 28A, 1781-1795.

Barbier, D., Gey, N., Allain, S., Bozzolo, N. \& Humbert, M. (2008) Analysis of the tensile behavior of a TWIP steel based on the texture and microstructure evolutions. Mat. Sci. Eng. A-Struct. 500, 196-206.

Bouaziz, O., Allain, S.\& Scott, C. (2008) Effect of grain and twin boundaries on the hardening mechanisms of twinning-induced plasticity steels. Scripta Mater. 58, 484-487.

Bracke, L., Penning, J. \& Akdut, N. (2007) The influence of Cr and N additions on the mechanical properties of FeMnC steels. Metall. Mater. Trans. A 38A, 520-528.

Christian, J.W. \& Mahajan, S. (1995) Deformation twinning. Prog. Mater. Sci. 39, 1-157.

Dastur, Y.N. \& Leslie, W.C. (1981) Mechanism of work hardening in Hadfield manganese steel. Metall. Mater. Trans. A 12A, 749759.

De Almeida, L.H., Le May, I. \& Emygdio, P.R.O. (1998) Mechanistic modeling of dynamic strain aging in austenitic stainless steels. Mater. Charact. 41-4, 137-150.

El-Danaf, E., Kalidindi, S.R. \& Doherty, R.D. (1999) Influence of grain size and stacking-fault energy on deformation twinning in fcc metals. Metall Mater Trans A 30A, 1223-1233.

Fanta, A.B. \& Zaefferer, S. (2008) Relationship between microstructure and texture evolutions during cold deformation of TWIP steels. Proceedings of the 15th Int. Conf. on Textures of Mater. ICOTOM 15, Pittsburgh, Pennsylvania.

Fundenberger, J.J., Morawiec, A., Bouzy, E. \& Lecomte, J.S. (2002) Polycrystal orientation maps from TEM. Ultramicroscopy 96, 127137.

Fundenberger, J.J., Morawiec, A., Bouzy, E. \& Lecomte, J.S. (2003) System for creating orientation maps using TEM. Mater. Chem. Phys. 81, 535537.

Grassel, O., Kruger, L., Frommeyer, G. \& Meyer, L.W. (2000) High strength Fe-Mn-(Al, Si) TRIP/TWIP steels development - properties - applications. Int. J. Plasticity 16, 1391-1409.

Hamdi, F. \& Asgari, S. (2008) Evaluation of the role of deformation twinning in work hardening behavior of face-centered-cubic polycrystals. Metal. Mater. Trans. A 39A, 294-303.

Hull, D. (1961) The initiation of slip at the tip of a deformation twin in $\alpha$-iron. Acta Metal. 9, 191-204.
Humphreys, F.J. (2001) Grain and subgrain characterization by electron backscatter diffraction. J. Mater. Sci. 36, 3833-3854.

Humphreys, F.J. (2004) Characterisation of fine-scale microstructures by electron backscatter diffraction. Scripta Mater. 51, 771-776.

Hutchinson, B. \& Ridley, N. (2006) On dislocation accumulation and work hardening in Hadfield steel. Scripta Mater. 55, 299-302.

Jorge-Badiola, D., Iza-Mendia, A. \& Gutiérrez I. (2007) Evaluation of intragranular misorientation parameters measured by EBSD in a hot worked austenitic stainless steel. J. Microsc. 228, 373-383.

Kalidindi, S.R. (1998) Modeling the strain hardening response of low SFE fcc alloys. Int. P. Plasticity 14, 1265-1277.

Kalidindi, S.R. (2001) Modeling anisotropic strain hardening and deformation textures in low stacking fault energy fcc metals. Int. J. Plasticity 17, 837-860.

Karaman, I., Sehitoglu, H., Gall, K., Chumlyakov, Y. I. \& Maier, H.J. (2000) Deformation of single crystal Hadfield steel by twinning and slip. Acta Mater. 48, 1345-1359.

Mahajan, S. \& Chin, G.Y. (1973) Twin-slip, twin-twin and slip-twin interactions in Co-8 wt.\% Fe alloy single crystals. Acta Metal. 21-2, 173-179.

Mason, T.A., Bingert, J.F., Kaschner, G.C., Wright, S.I. \& Larsen, R.J. (2002) Advances in deformation twin characterization using electron back scattered diffraction data. Metall. Mater. Trans. A 33-3, 949-954.

Meng, L., Yang, P., Xie, Q., Ding, H. \& Tang, Z. (2007) Dependence of deformation twinning on grain orientation in compressed high manganese steels. Scripta Mater. 56, 931-934.

Rémy L. (1978) Kinetics of fcc deformation twinning and its relationship to stress-strain behavior. Acta Metall. 26, 443-451.

Rémy L. (1981) The interaction between slip and twinning systems and the influence of twinning on the mechanical behavior of fcc metals and alloys. Metall. Mater. Trans. A 12A, 387-408.

Salem, A.A., Kalidindi, S.R. \& Doherty, R.D. (2003) Strain hardening of titanium: role of deformation twinning, Acta Mater. 51-14, 42254237.

Schwarzer, R.A. (1991) A review of the analysis of local texture by electron diffraction. Texture Microstruct. 14, 241-244.

Scott, C., Guelton, N., Allain, S., Farral, M. \& Cugy, P. (2005) The development of a new Fe-Mn-C austenitic steel for automotive applications. Proceeding of the MSET'05 Conference. Pittsburgh, Pennsylvania. MST.

Shun, T.S., Wan, C.M. \& Byrne, J.G. (1992) A study of work hardening in austenitic Fe-Mn-C and Fe-Mn-Al-C alloys. Acta. Metall. Mater. 40-12, 3407-3412.

Yang, P., Xie, P., Meng, L., Ding, H. \& Tang, Z. (2006) Dependence of deformation twinning on grain orientation in a high manganese steel. Scripta Mater. 55, 629-631. 